\title{
Performance Of some Corrosion Inhibitors For Carbon Steel In Hydrochloric Acid
}

Qasim J. M. Slaiman ${ }^{\text {a }}$, Basim O. Hasan ${ }^{a}$, Hayder M. Turki ${ }^{b}$

a. Chemical Engineering Dept.- Nahrain University

b.State Company for Oil Project (SCOP), Ministry of Oil

$\underline{\text { Abstract: }}$

Corrosion tests on

commercial carbon steel pipe in aerated $0.1 \mathrm{~N} \mathrm{HCl}$ solution under static and flow conditions with ranges of rotation velocity of 400 $1400 \mathrm{rpm}$ and temperature of $35-$ $60^{\circ} \mathrm{C}$, were carried out by weight loss method, in absence and presence of several inhibitors which were thiourea, ethylenediamine, diethanolamine and formaldehyde as an adsorption type inhibitors in concentration range $400-2000$ ppm using rotating cylinder arrangement. The experimental results showed that the corrosion rate in absence and presence of inhibitors is increased with the increasing temperature of the corrosive solution and the rotational velocity and is decreased with increasing the inhibitors concentration for the whole range of temperatures and rotational
velocities. Highest inhibition efficiency was attained by thiourea with considerable efficiencies for other inhibitors. The order of corrosion inhibitors efficiencies was as follows: thiourea > ethylenediamine > diethanolamine > formaldehyde. Under static conditions maximum inhibition efficiency obtained was $77.59 \%$ for thiourea and the minimum inhibition efficiency was $37.12 \%$ for formaldehyde depending on inhibitor concentration and temperature. Also the results revealed that the inhibitors efficiency increases with increasing its concentration and decreases with increasing agitation speed and temperature. The thiouurea was found to be good inhibitor even at high agitation velocity while the formaldehyde 
failed to inhibit corrosion at high

velocity.

Key words: corrosion inhibitors, carbon steel, hydrochloric acid, agitation velocity, inhibition efficiency.

\section{Introduction :}

The corrosion of metals

remains a world-wide scientific problem as it affects the metallurgical, chemical and oilindustries. The increasing interest in the manufacture of hydrochloric acid has created the need for obtaining information on the corrosion resistance of mild steel to hydrochloric acid attack. Of particular importance also is the need to introduce certain organic compounds as inhibitors into the mild steel/corrodent system to prevent corrosion of the mild steel. Mild steel corrosion in acid solution has been effectively controlled by the use of organic substances containing nitrogen, oxygen, or sulphur in the conjugated system as inhibitors $[1,2]$. The corrosion of mild steel in $\mathrm{HCl}$ solution is
Aheterogeneous one, comprising of anodic and cathodic reactions [3].

Corrosion inhibitor is a substance which, when added to an Environment decreases the rate of attack by the environment of a metal. Corrosion inhibitors are usually added in small amounts to acids, cooling waters, steam, and other environments, either continuously or intermittently to prevent serious corrosion. The efficiency of an inhibitor is thus expressed by the following equation: Inhibitor efficiency $(\%)=$ $100\left(\mathrm{CR}_{\text {uninhibited }}-\mathrm{CR}_{\text {inhibited }} / \mathrm{CR}_{\text {uninhibited }}\right)$ where $\mathrm{CR}_{\text {uninhibited }}$ is the corrosion rate of the uninhibited system and $\mathrm{CR}_{\text {inhibited }}$ is the corrosion rate of the inhibited system $[4,5]$. The range of inhibitors is wide and the way to classify them is by considering their mechanism action and their composition: adsorption type 
inhibitors,

hydrogen-evolution

poisons, scavengers, oxidizers, vapor-phase inhibitors etc.

Currently, researches are focused on producing and testing environmentally friendly corrosion inhibitors. A feasible solution to this problem is the use of corrosion inhibitors derived from amino compounds; these compounds constitute an important potential class of corrosion inhibitors. Amino acids have been successfully used as corrosion inhibitors in many practical applications, because they are friendly to the environment and have very low toxic [6]. This work aims to investigate the performance of some selected organic substances as corrosion inhibitors which are thiourea, ethylenediamine, diethanolamine, and formaldehyde to inhibit corrosion of carbon steel in aerated $0.1 \mathrm{~N}$ HCL under static and flow conditions in order to assess the influence of temperature, hydrodynamic, and concentration on the performance of these inhibitors.

\section{Experimental work:}

\section{The Fig (1) shows the} experimental arrangement that was used to investigate the inhibitive action of formaldehyde (HCHO), thiourea (CSN2H4), ethylenediamine $\left(\left(\mathrm{H}_{2} \mathrm{~N}-\mathrm{CH}_{2}-\mathrm{CH}_{2}-\mathrm{NH}_{2}\right)\right.$ and diethanolamine $\quad\left(\mathrm{HN}\left(\mathrm{CH}_{2} \mathrm{CH}_{2} \mathrm{OH}\right)_{2}\right)$ as adsorption type inhibitors on the corrosion behavior of carbon steel in $0.1 \mathrm{~N} \mathrm{HCl}$ aerated solution, for temperatures of $35^{\circ} \mathrm{C}, 45^{\circ} \mathrm{C}$ and 60 ${ }^{\circ} \mathrm{C}$ at rotational speeds for specimen of $0,400,700,1000$ and $1400 \mathrm{rpm}$. The electrolyte was hydrochloric acid of concentration $37 \%$ which has a molecular weight of $36.64 \mathrm{~g} / \mathrm{gmol}$ and a density of $1180 \mathrm{gm} / \mathrm{cm}^{3}$.The concentrated acid was diluted using distilled water to obtain the required normality of $0.1 \mathrm{~N}$. Acetone and ethanol of concentrations $\cong 99 \%$ were used for sample degreasing and cleaning. The experimental apparatus was composed of the followings: thermometers to measure the temperature, digital $\mathrm{pH}$-meter to measure and monitor the $\mathrm{pH}$ of the 
working solution during the test run (the $\mathrm{pH}$-meter was calibrated using buffer solutions of $\mathrm{pH} \mathrm{4,7,} \mathrm{and} \mathrm{9),}$ water bath with temperature controller to heat and control the solution temperature, high accuracy digital balance with 4 decimal points for weight loss determination, vibrationless motor to rotate the specimen with various velocities. Carbon steel (CS) pipe was used as a working electrode in a cylindrical shape for weight loss measurements with a length of $30 \mathrm{~mm}$, outside diameter of $25 \mathrm{~mm}$ and inside diameter of $20 \mathrm{~mm}$. The carbon steel specimen composition is shown in Table 1 .

Table( 1) Composition of the studied carbon steel specimen.

\begin{tabular}{||l||l||l|l||l|l||}
\hline Element & C & Mn & P & S & Fe \\
\hline \hline $\begin{array}{l}\text { Weight } \\
(\%)\end{array}$ & 0.1649 & 0.5027 & 0.0020 & 0.0068 & Rest \\
\hline
\end{tabular}

Cylindrical specimen of area $\pi *$ $0.025 * 0.03 \mathrm{~m}^{2}$ and wall thickness of $0.005 \mathrm{~m}$ was immersed in a solution of $\mathrm{HCl}$ of a strength $0.1 \mathrm{~N}$ in order to assess the corrosion rates by weight loss method. Before each experimental run, the metal specimen was washed by tap water followed by distilled water, dried with clean tissue, immersed in annular ethanol for 5 minutes, rinsed with clean acetone and dried with clean tissue. The specimen was then stored in a desiccator over highly active silica gel for $2 \mathrm{~h}$ before use, then they was weighed and directly exposed to the corrosion environment [7-10]. For these measurements the metal sample was installed on the motor shaft and completely immersed in 2.5 liters corrosive solution contained in 3 liters volume beaker. It was exposed for period of $2 \mathrm{~h}$ at specified temperature, concentration of inhibitor, and rotational velocity. After the exposure to the corrosion environment, the specimen was 
washed by tap water then brushed by smooth brush under running tap water to remove the corrosion products. After that the specimen was washed by tap water, distilled water, and dried with clean tissue, and kept in desiccator for $2 \mathrm{~h}$, and then weighed [9, 10]. Each run was repeated twice with a third run when reproducibility was in doubt. The above procedure was repeated for specimens in absence and presence of inhibitors for the whole investigated range of rotational velocity and temperature.

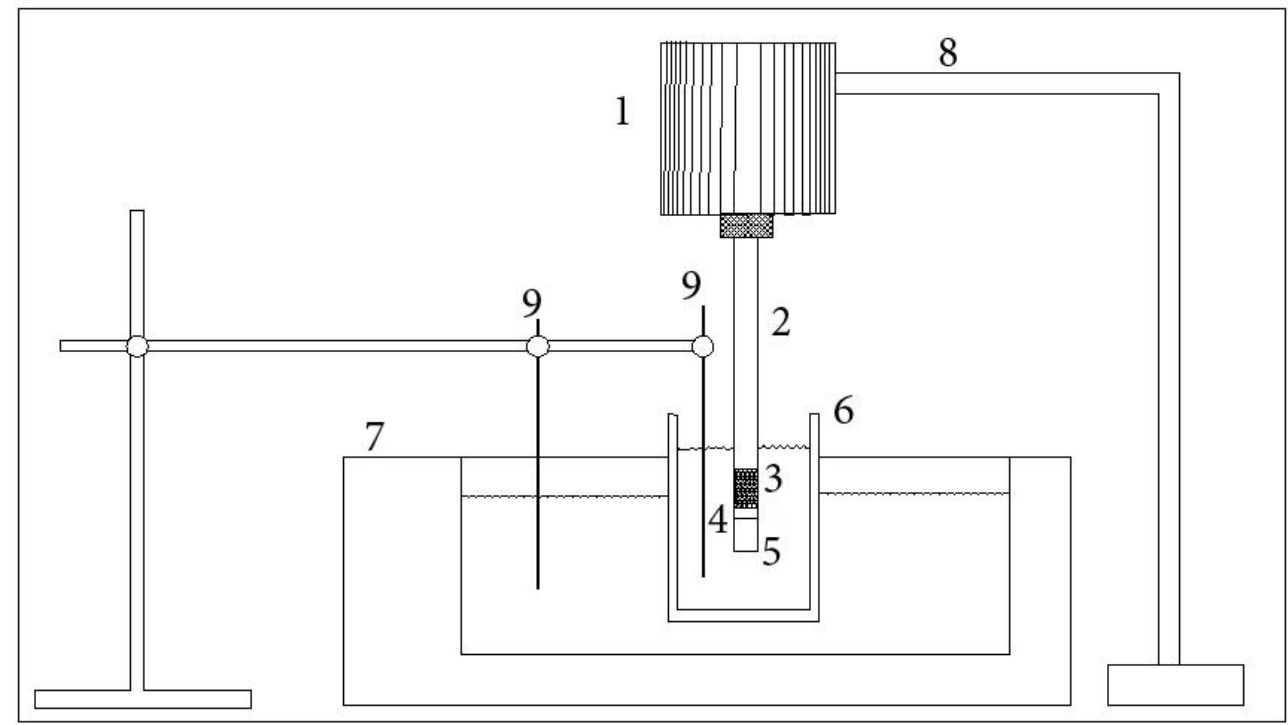

Fig. (1): Sketch showing the details of the rotating holder. 1-motor for rotating the specimens 2- Teflon rod 3- cylindrical specimen 4- Teflon washer 5- Teflon cap 6- beaker 7- water bath 8stand to hold the motor 9- thermometer.

\section{$\underline{\text { Results and discussion: }}$}

\section{Effect of temperature and velocity}

\section{in the absence of inhibitors}

The effect of velocity is expressed by Reynolds number $(\mathrm{Re})$ to include the change in physical properties (solution density and viscosity) with temperature change, where :

$$
\operatorname{Re}=\frac{\rho \times d^{2} \times N}{\mu}
$$

Where $\rho\left(\mathrm{kg} / \mathrm{m}^{3}\right)$ is the solution density, $\mu(\mathrm{kg} / \mathrm{m} . \mathrm{s})$ is the solution viscosity, $u$ is the agitation velocity $(\mathrm{m} / \mathrm{s}), \quad \mathrm{d}$ is the pipe (specimen) diameter $(\mathrm{m})$, and $\mathrm{N}$ is the rotational velocity (revolution/s). fig (2 )shows 
the variation of corrosion rate of carbon steel with Reynolds number $(\operatorname{Re}=\rho \mathrm{d} u / \mu)$ at three temperatures in $0.1 \mathrm{~N} \mathrm{HCl}$ before addition of inhibitors. It is evident that at a particular temperature, the corrosion rate increases with Re. For aerated systems the increase in the corrosion rate with $\operatorname{Re}$ (or rotational velocity) is due to the increase of oxygen transport from solution bulk to the metal surface by thinning the diffusion boundary layer thickness in the wall vicinity which represents the main resistance to mass transport and hence results in higher corrosion rate [11- 14]. Also Fig(2) indicates that under static conditions the corrosion rate increases with temperature. It is showing the values of $175.8 \mathrm{gmd}$, $239.5 \mathrm{gmd}$, and $476.7 \mathrm{gmd}$ at $35^{\circ} \mathrm{C}$, $45{ }^{\circ} \mathrm{C}$, and $60{ }^{\circ} \mathrm{C}$ respectively. Similarly at a particular Re the CR increased with increasing the temperature of the acid solution. This behavior can be interpreted as follows: increasing temperature leads to change three variables. Firstly, increasing temperature accelerates the reaction rate as dictated by Arrhenius equation $[13,15]$. Secondly, when the temperature increases, the molecular diffusion coefficient of dissolved oxygen increases leading to increase the corrosion rate $[11,16]$. Thirdly, as the temperature increases the oxygen solubility decreases $[11,13,17,18]$ the factor that leads to decrease the corrosion rate. Hence, the influence of first two factors is more predominant than the last one (dissolved oxygen). This shows the corrosion process is not totally similar or identical under static and hydrodynamic conditions. 


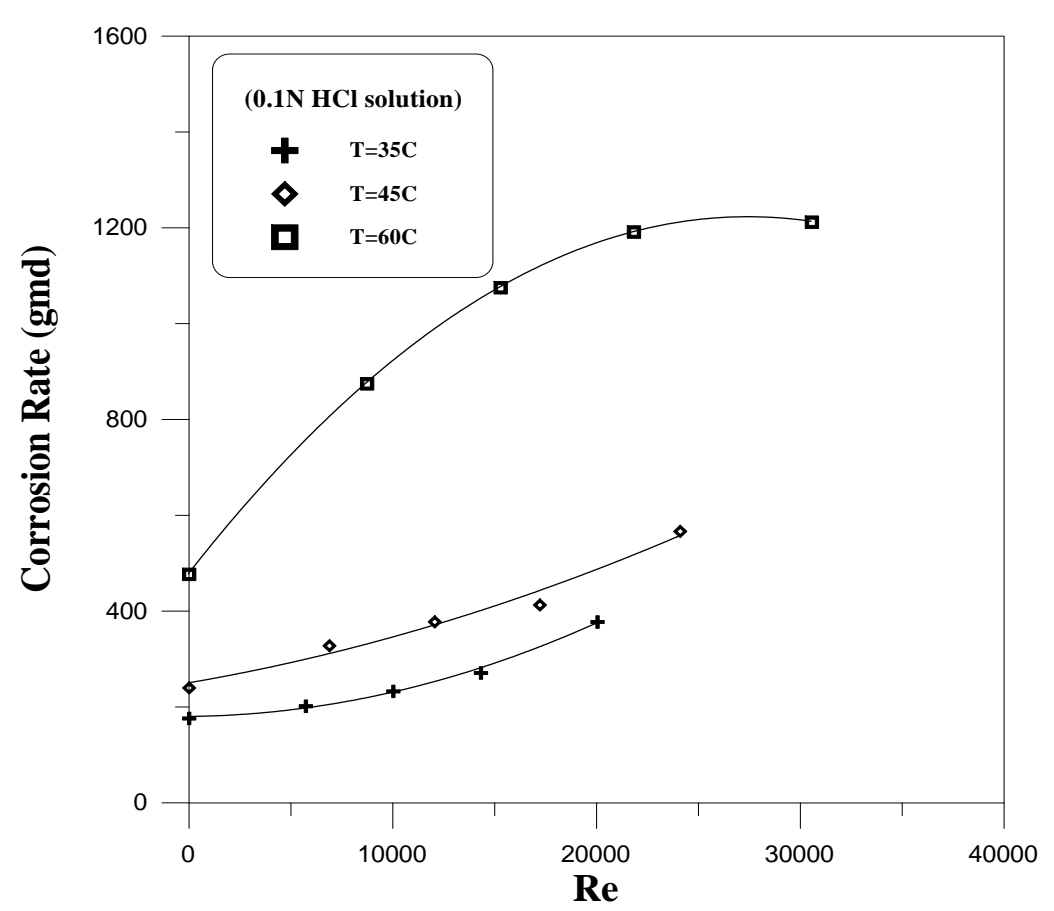

Fig(2) Corrosion Rate versus Reynolds Number.

\section{Effect of inhibitors and the role of}

\section{velocity and temperature:}

The fig (3) to (6) show the

corrosion rate versus $\mathrm{Re}$ in the presence of formaldehyde, diethanolamine, ethylenediamine, and thiourea at various concentrations for $35^{\circ} \mathrm{C}$ respectively. These figures show the influence of concentration of each inhibitor on the corrosion rate of carbon steel. It is evident that the corrosion rate increases with $\mathrm{Re}$ in presence of all inhibitors and generally the higher the inhibitor concentration, is the lower the corrosion rate will be. In case of stationary conditions $(\operatorname{Re}=0)$, the minimum corrosion rates are obtained at highest concentrations of inhibitors. So, the thiourea exhibits the best corrosion inhibition value. The same trend is valid in the case of flow conditions $(\mathrm{Re}>0)$. Organic compounds inhibitors decrease the corrosion rate by one of two ways: either adsorbed on the metal surface, forming a thin two-dimensional (2-D) film. This type can be further subdivided into non-selective and 
selective physisorption and chemisorptions or by forming threedimensional (3-D) layer emerges on the metal surface resulting from, for example, the chemical reaction of an

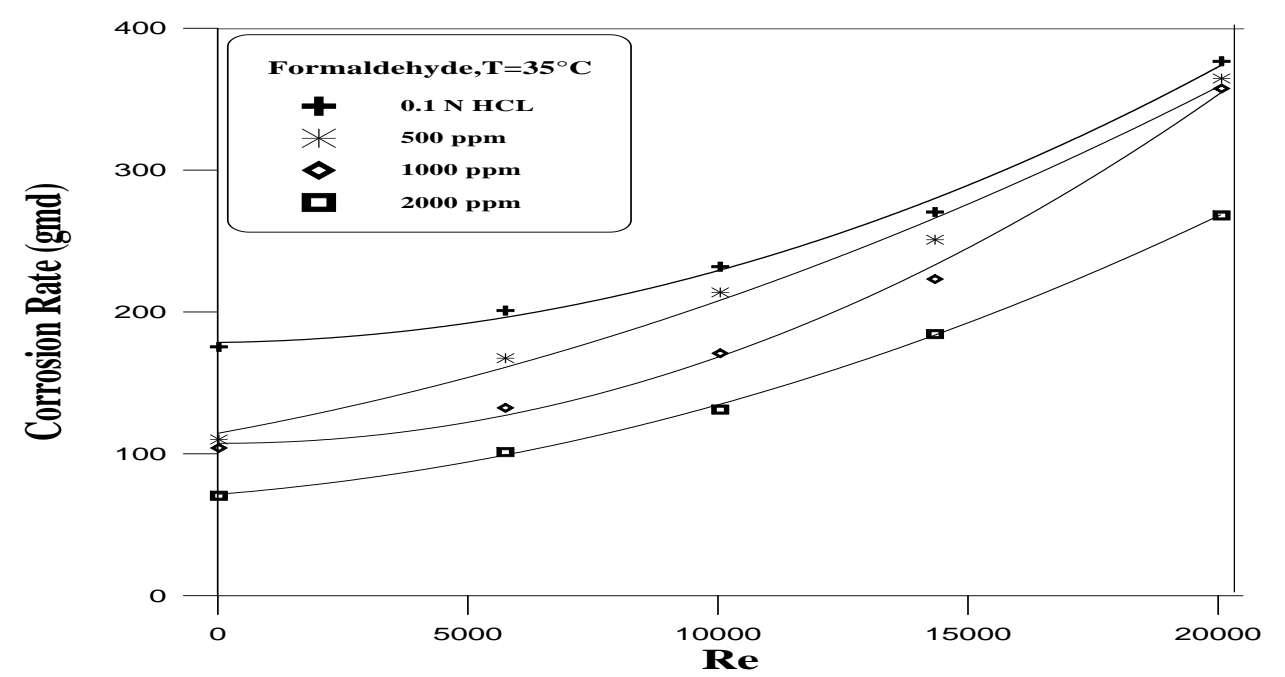

Fig (3) variation of corrosion rate with Reynolds number in the presence of formaldehyde inhibitor at $\mathrm{T}=35^{\circ} \mathrm{C}$.

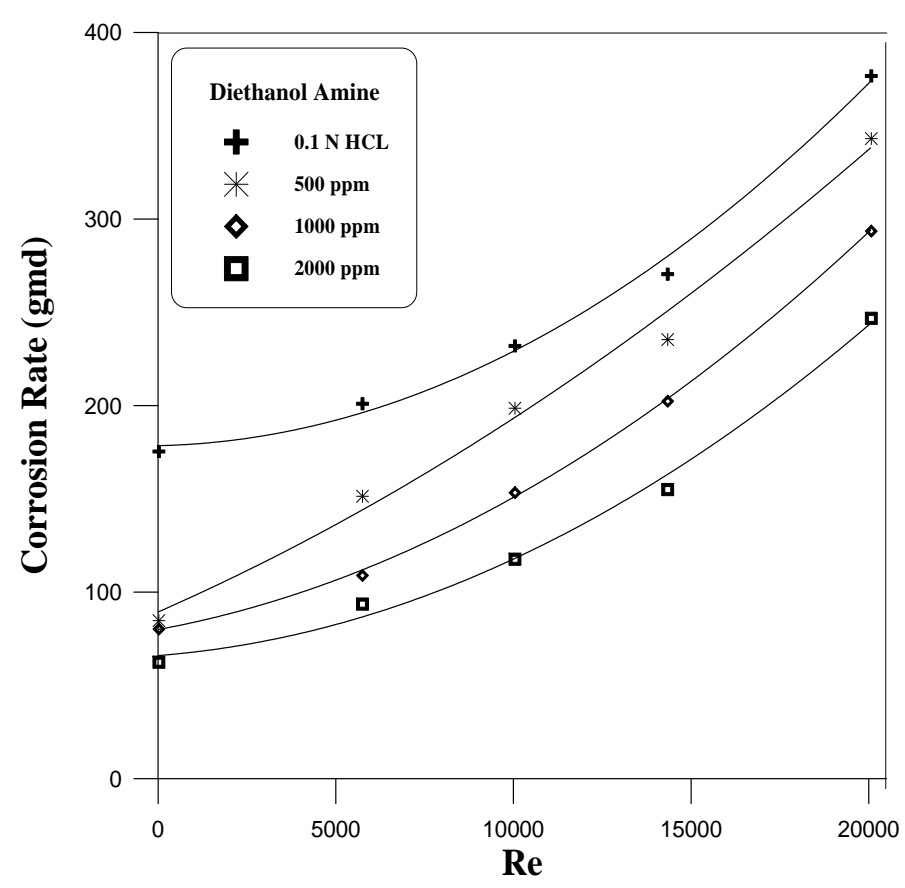

Fig (4) variation of corrosion rate with Reynolds number in presence of diethanolamine inhibitor at $\mathrm{T}=$ $35^{\circ} \mathrm{C}$. 


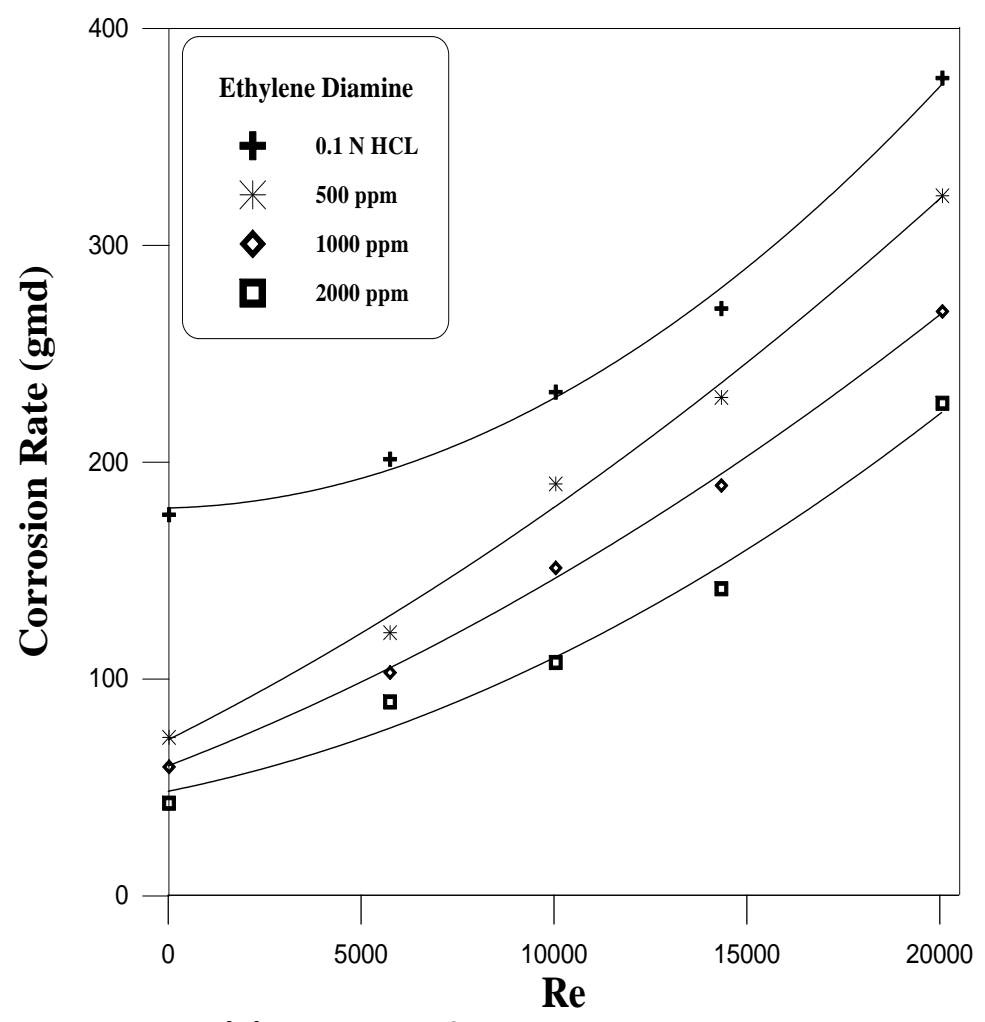

Fig (5) variation of corrosion rate with Reynolds number in presence of ethylenediamine Inhibitor at $\mathrm{T}=35^{\circ} \mathrm{C}$.

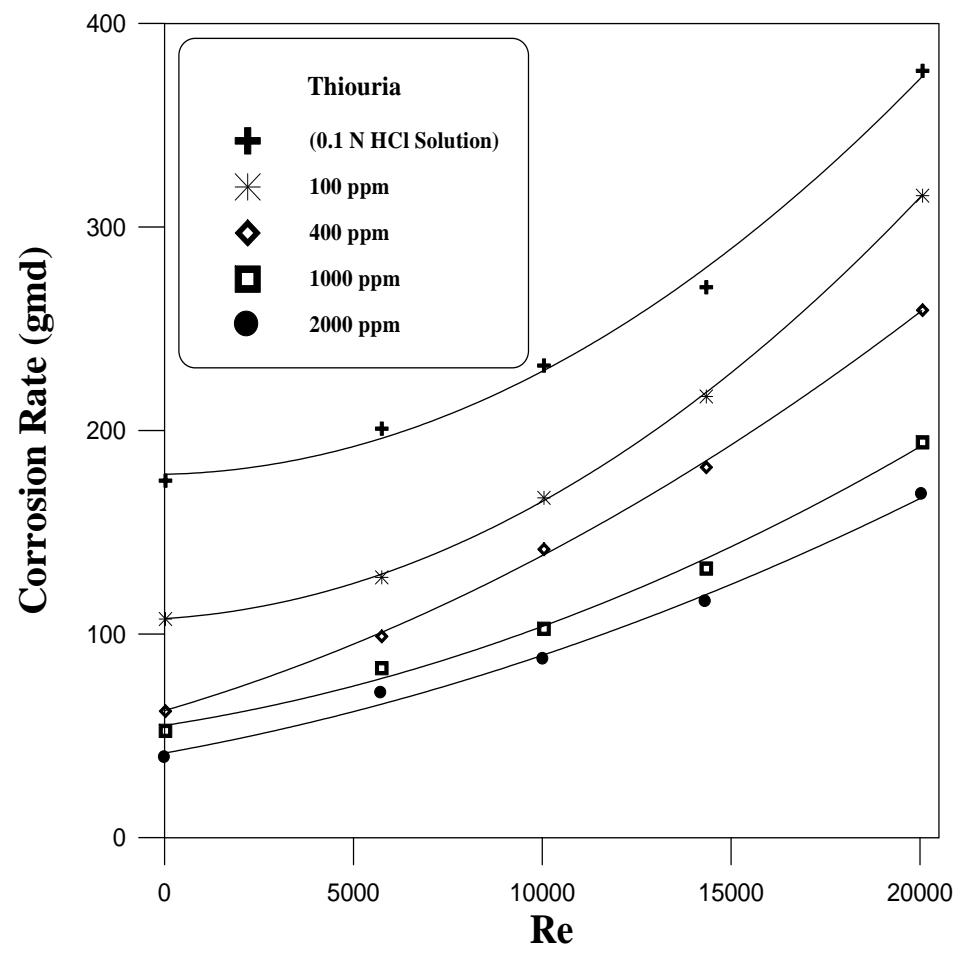

Fig (6) variation of corrosion rate with Reynolds number in presence of thiourea inhibitor at $\mathbf{T}=$ $35^{\circ} \mathrm{C}$. 
figs (7) to (9) show comparison among corrosion rates in the presence of formaldehyde, diethanolamine, ethylenediamine and thiourea at various concentrations for $\mathrm{T}=35{ }^{\circ} \mathrm{C}$. The fig reveal that increasing inhibitor concentration decreases the corrosion rate of carbon steel It is clear that the four inhibitors give different corrosion rates. From Fig. (7), at stationary conditions $(\mathrm{Re}=0), 400 \mathrm{ppm}$ of thiourea reduced the CR from 175.8 gmd to $62.5 \mathrm{gmd}$, i.e. $64.4 \%$, and at maximum $\operatorname{Re}$ of 20000 it reduced the CR from 377.2 gmd to 259.5 gmd, i.e. $31 \%$. At the same conditions the, $500 \mathrm{ppm}$ of diethanolamine reduced the $\mathrm{CR}$ from 175.8 to $85 \mathrm{gmd}$, i.e $51.5 \%$ at stationary conditions and from 377.2 gmd to $343.5 \mathrm{gmd}$, i.e. $8.9 \%$ at $\mathrm{Re}=20000,500 \mathrm{ppm}$ of ethylenediamine reduced the $\mathrm{CR}$ from 175.8 gmd to 73.1 gmd,i.e. $58 \%$ at stationary conditions and from 377.2 gmd to 322.9 gmd, i.e. $14.4 \%$ at $\mathrm{Re}=20000,500 \mathrm{ppm}$ of Formaldehyde reduced the CR from 175.8 gmd to 110.5 gmd, i.e. $37 \%$ under stationary conditions and from 377.2 gmd to 365.0 gmd, i.e. $3.2 \%$ at $\mathrm{Re}=20000$. Fig. 9 shows that 2000 ppm of each inhibitor reduced the $\mathrm{CR}$ rate as follows, under stationary conditions : thiourea $77 \%$, diethnolamine $64 \%$, ethylenediamine $75.6 \%$, Formaldehyde $59.7 \%$, while under flow conditions at $\mathrm{Re}=20000$, the inhibition efficiencies are 55.3\%, $34.5 \%, \quad 39.8 \%$, and $28.8 \%$ respectively. Hence it is evident that the thiourea gives the highest inhibition efficiency in stationary and flow conditions, followed by ethylenediamine, diaethanolamine, and formaldehyde. [22] found that ethylenediamine inhibit the corrosion of mild steel in deaerated $\mathrm{HCl}$ under stationary conditions by $65 \%$ when its concentration was $4.2 \times 10^{-3} \mathrm{M}$ and $94-98 \%$ when its concentration was $3.39 \times 10^{-2}[23]$ stated that amines are cationic type inhibitors. They are often added to $\mathrm{HCl}$-rich environments. When the system involved is ferrous metal, neutralizing amines work by the mechanism that modifies the $\mathrm{pH}$ of the electrolyte 
and thus inhibiting rust formation. [24] demonstrated that the behavior of ethylenediamine and thiourea on the corrosion of mild steel in $1 \mathrm{M}$ hydrochloric acid solution are mixed-type inhibitors, i.e. it control both anodic reaction (carbon steel dissolution) and cathodic reaction (hydrogen reduction and oxygen reduction on the carbon steel surface). [25] stated that thiourea and its derivatives decrease the corrosion rate of mild steel in aqueous solutions of $\mathrm{HCl}$ as well $\mathrm{H}_{2} \mathrm{SO}_{4}$, by forming adsorption layer on the metal surface to decrease the anodic reaction, i.e. it works as anodic inhibitor. [26] stated that thiourea simultaneously acts in both anodic and cathodic areas by decreasing the corrosion rate of mild steel (dissolution process of iron) in dilute $\mathrm{HCl}$ solution and decreasing the oxygen reduction and hydrogen evolution.

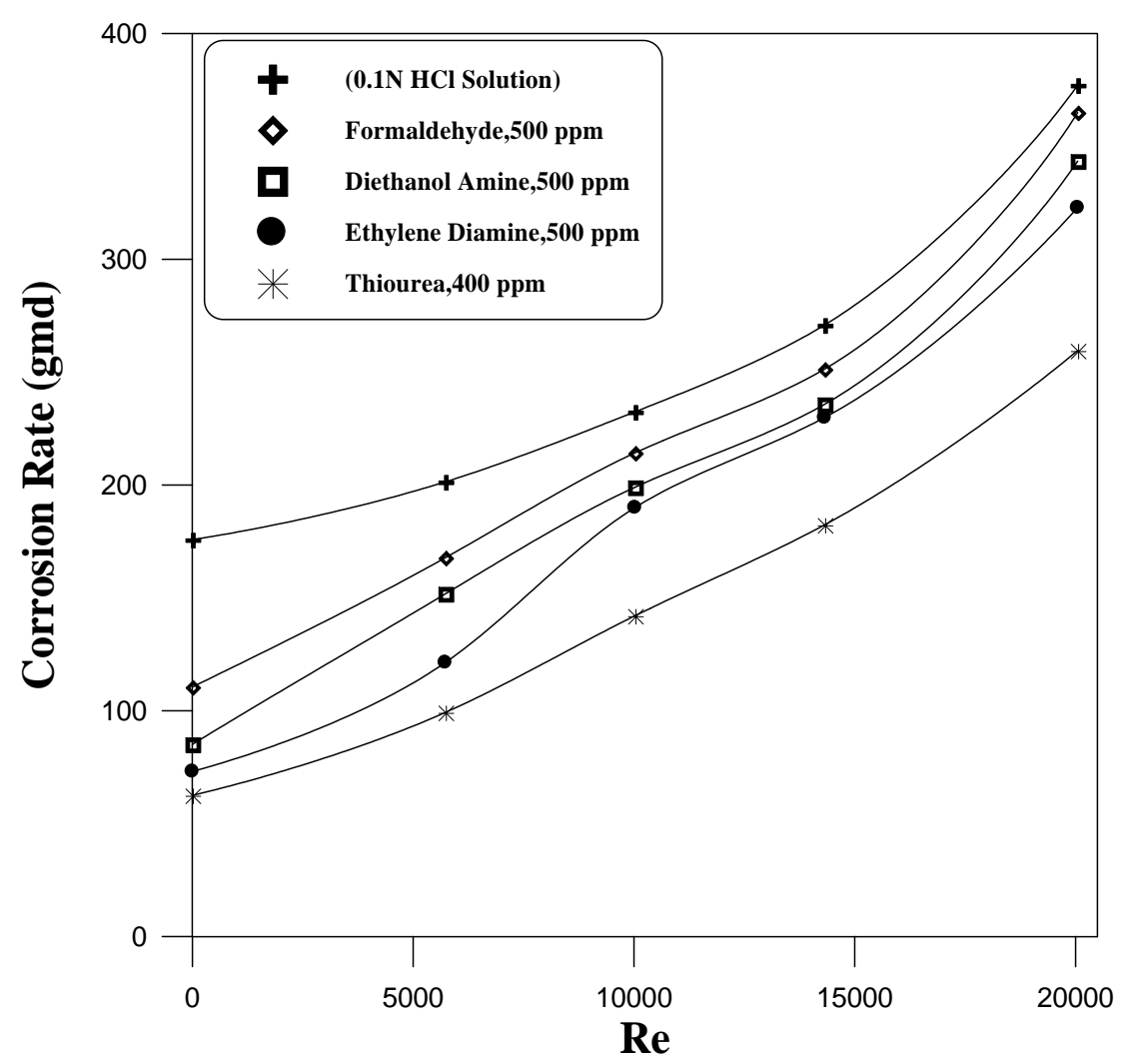

Fig(7) comparison among corrosion rates in presence of various inhibitors at $\mathrm{T}=35^{\circ} \mathrm{C}$. 


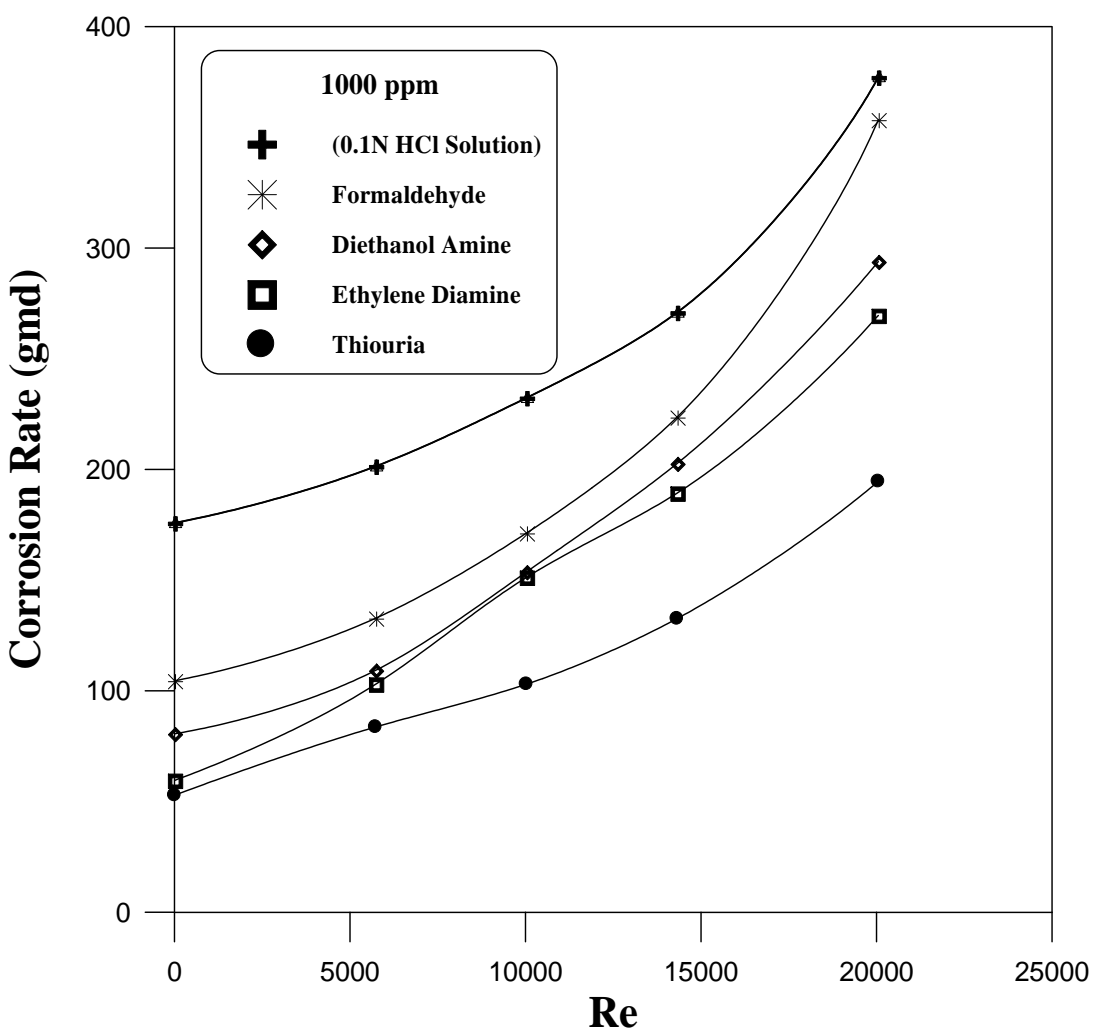

Fig (8) Comparison among Corrosion Rates in Presence of Various Inhibitors at $\mathrm{T}=35^{\circ} \mathrm{C}$.

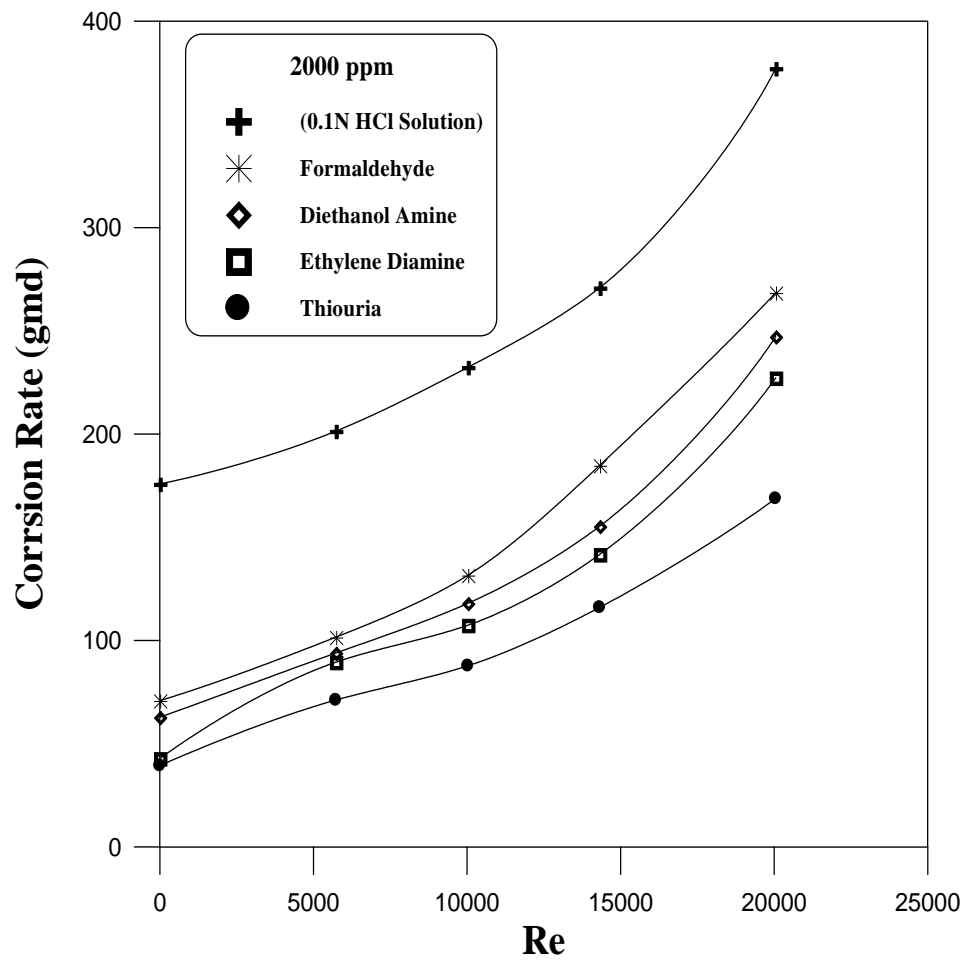

Fig (9) Comparison among corrosion rates of inhibitors at $\mathrm{T}=35^{\circ} \mathrm{C}$. 
fig (10) shows the comparison of inhibitors efficiencies at temperature of $35^{\circ} \mathrm{C}$. It can be seen that the efficiency of thiourea is the highest followed by ethylene diamine, diethanol amine, and formaldehyde inhibitor. The figure indicates that the efficiency of inhibitors decreases as the Re increases. This can be attributed to the fact that as $\operatorname{Re}$ (or velocity) increases, the shear forces exerted on the metal surface remove the adsorbed layer (protective layer) of the inhibitor from the metal surface or decrease its thickness leading to decrease the inhibitive action [27]. Also the Fig. reveals that the lowest effect of $\operatorname{Re}$ on the inhibitor efficiency is in the case of thiourea. This is another advantage of thiourea that it gives good inhibition even at high Re. Other types of inhibitors are shown to be poor inhibitors at high $\mathrm{Re}$, where, when Re becomes larger than 10000 , these inhibitors give inhibitor efficiency lower than $20 \%$ for the specified concentration.

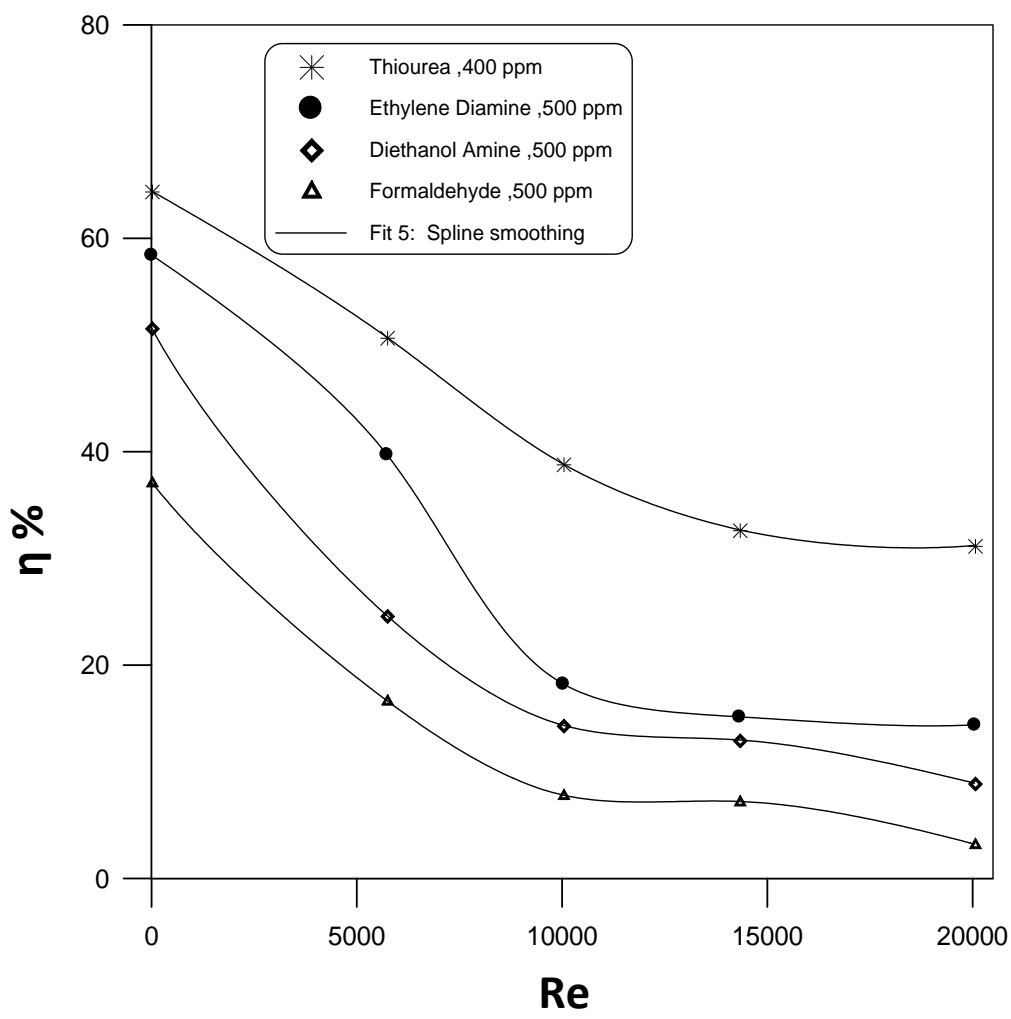

Fig (10) comparison among inhibitors efficiencies at $\mathrm{T}=35^{\circ} \mathrm{C}$. 
Figs. 11 to 14 show the variation of inhibition efficiency with $\operatorname{Re}$ at different inhibitor concentrations for all inhibitors used. It is clear that the inhibition efficiency increases considerably with increasing inhibitors concentrations up to $2000 \mathrm{ppm}$. This is in accordance with previous studies that considered the inhibition of steel corrosion in acids and neutral solutions [2, 6, 21, 27].
Observing Figs. 11 to 14 indicates that the efficiency of thiourea exhibits the lowest decrease with increasing Re. The efficiency of ethelynediamine and diethanolamine decreases considerably at high $\mathrm{Re}$ in a particular at low concentrations. The Efficiency of Formaldehyde decreases greatly with increasing Re. In other words formaldehyde cannot be used at high Re.

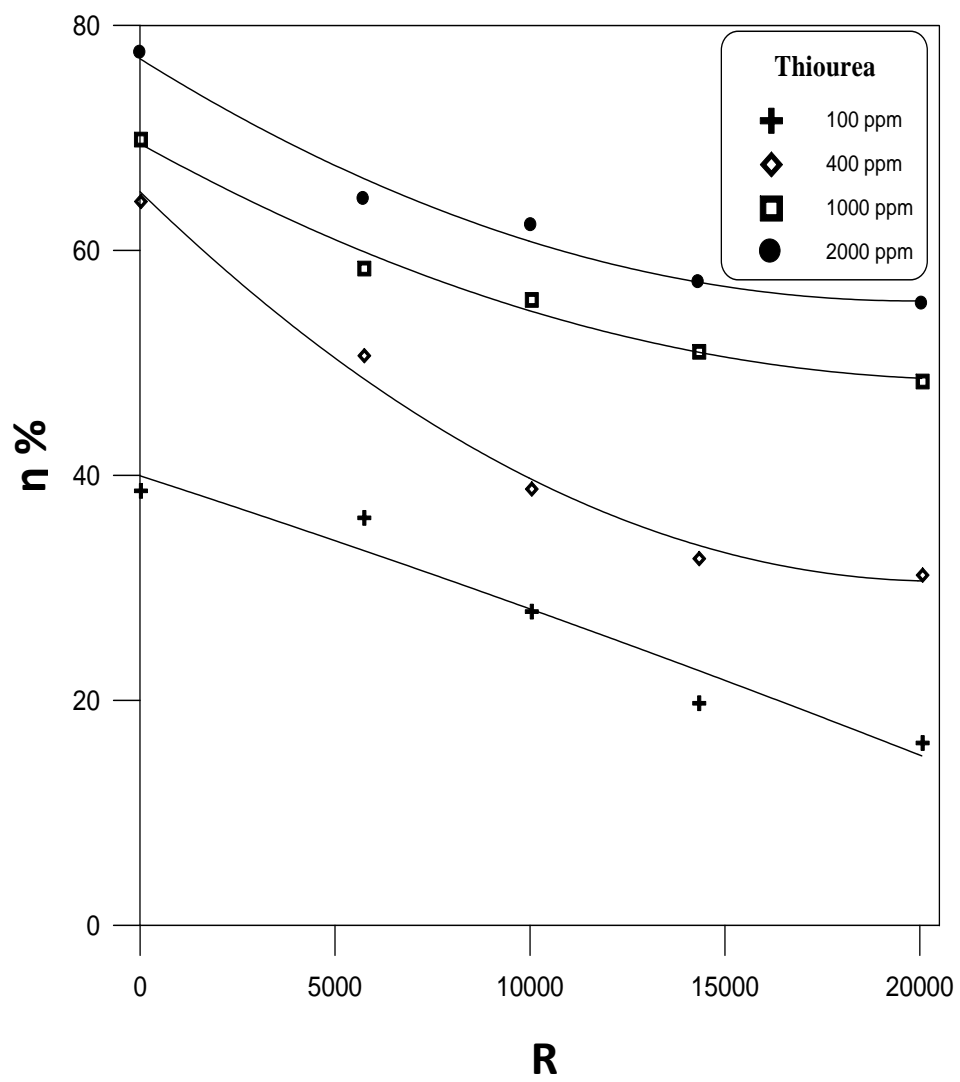

Fig (11) variation of inhibition efficiency with Reynolds number in presence of thiourea at $\mathrm{T}=35^{\circ} \mathrm{C}$. 


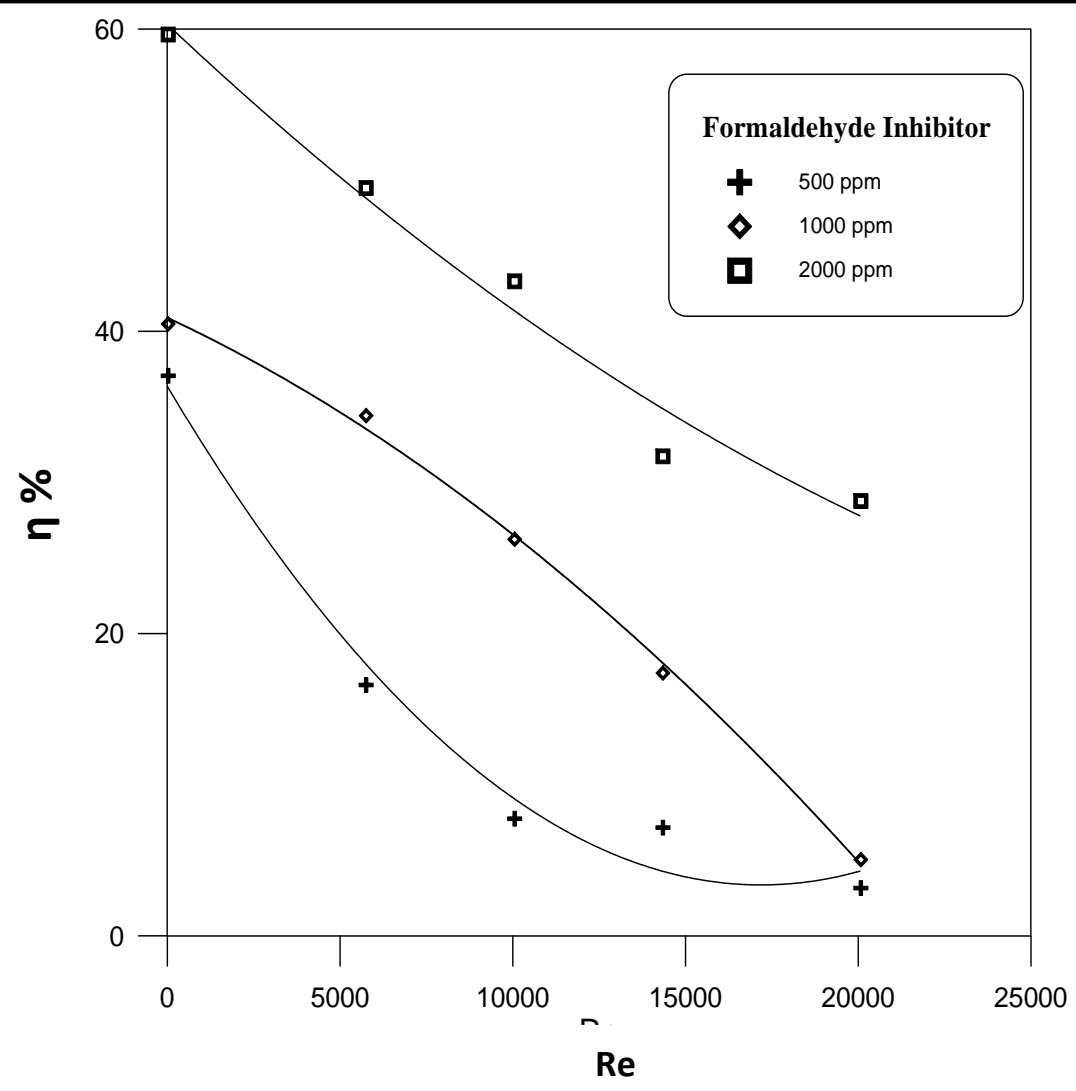

Fig (12) Variation of Inhibition Efficiency with Reynolds Number in Presence of Formaldehyde Inhibitor at $\mathrm{T}=35^{\circ} \mathrm{C}$.

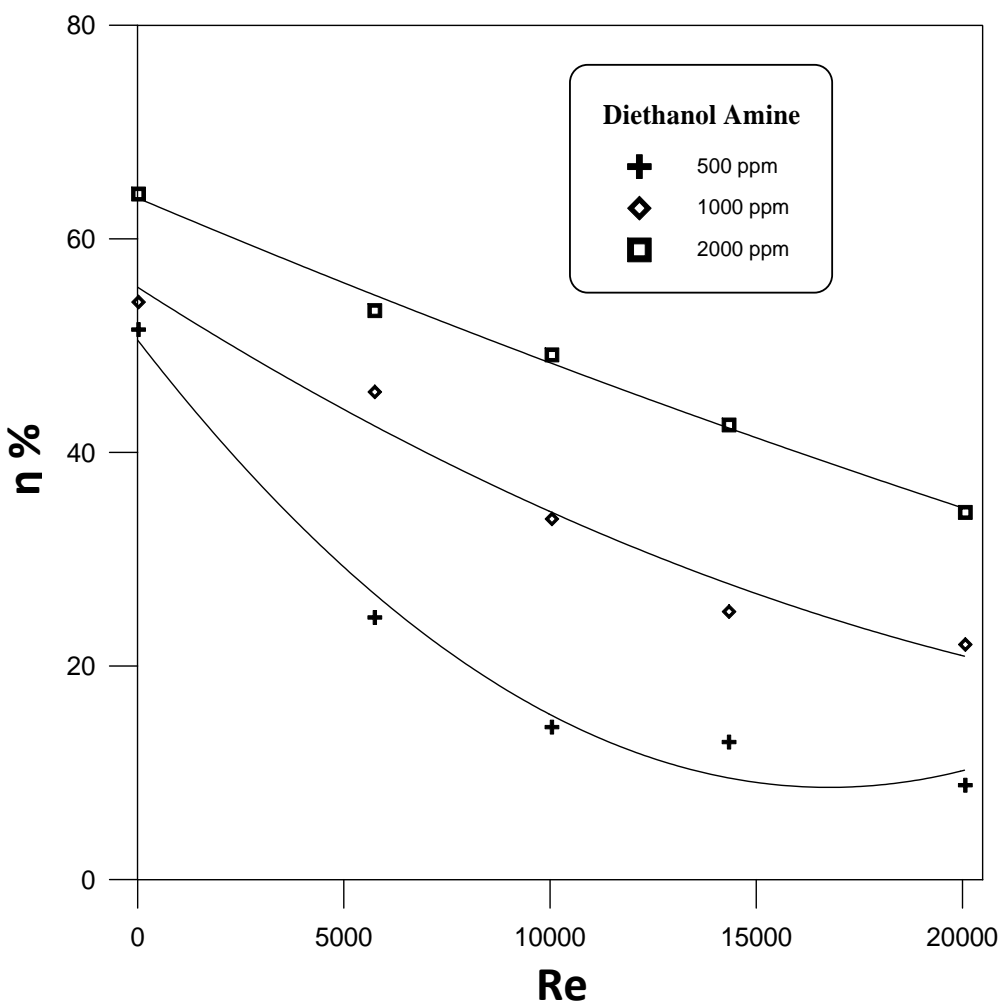

Fig (13): variation of inhibition efficiency with Reynolds number in presence of diethanolamine at $\mathrm{T}=35^{\circ} \mathrm{C}$. 


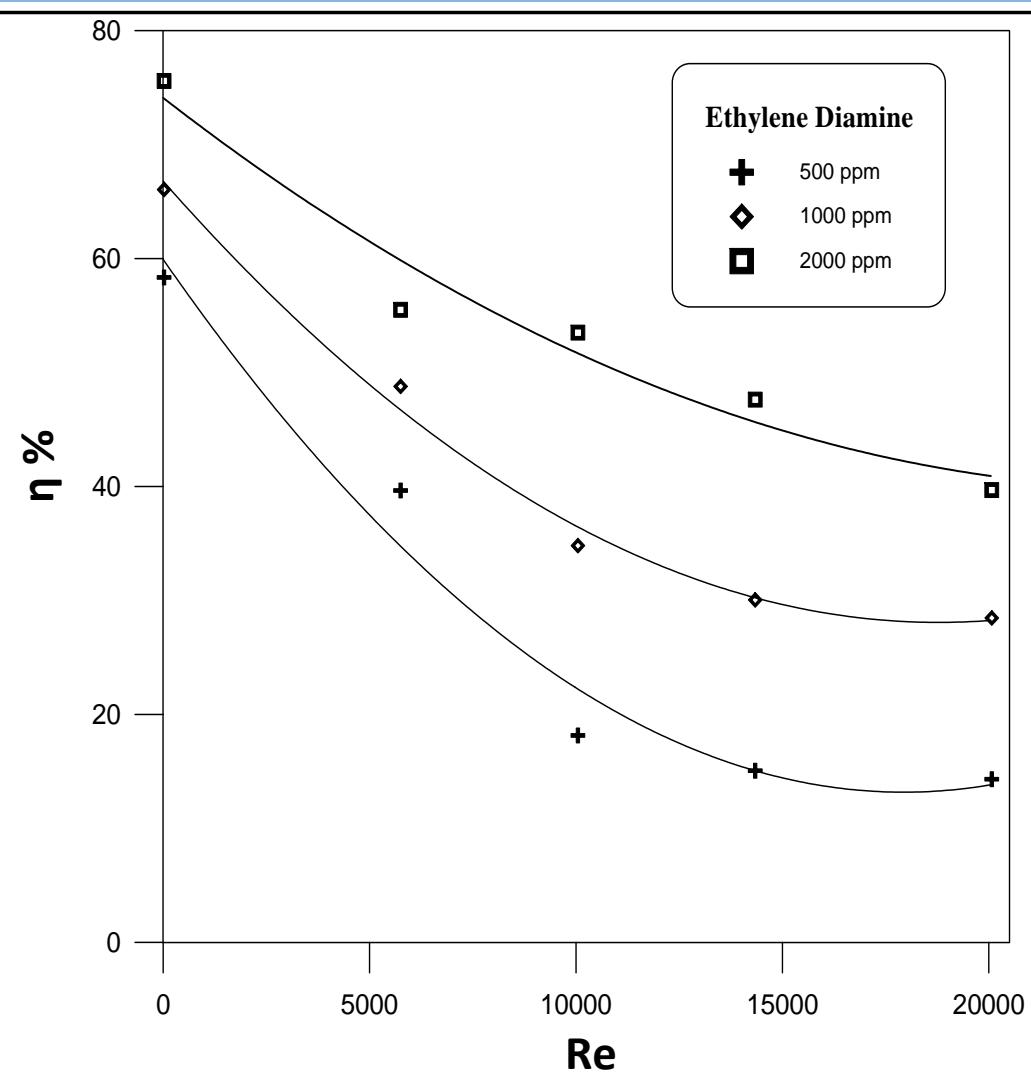

Fig (14) variation of inhibition efficiency with Reynolds number in presence of ethylenediamine at

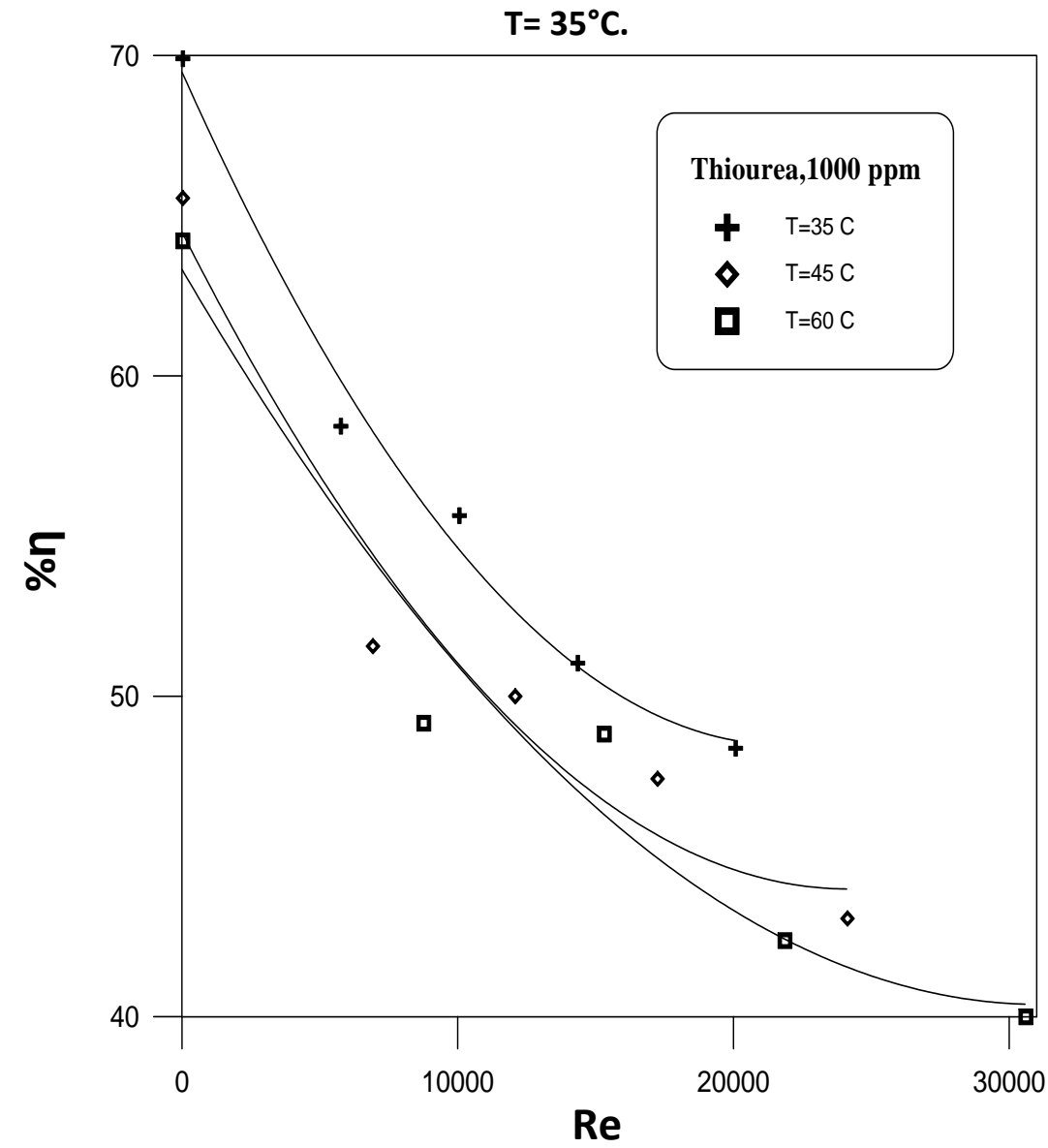

Fig (15) Inhibition Efficiency for Thiourea Inhibitor at Concentration of 1000 ppm versus Reynolds Number. 
Fig 15 shows the effect of temperature on the inhibition efficiency of thiourea. It is clear that the inhibition efficiency decreases with temperature rise for the investigated range $\left(35{ }^{\circ} \mathrm{C}\right.$ to $\left.60{ }^{\circ} \mathrm{C}\right)$ and Re. The decrease in efficiency with temperature may be attributed to the stability of adsorbed film of inhibitor molecules on the metal surface, which are more easily desorbed at higher temperature. As temperature increases Gibbs free energy rises to a higher value, so that some of the chemical bonds joining the molecules onto the metallic surface are impaired and film stability reduced. However, enthalpy has a roughly constant value in the temperature range tested depending on the tested compound [2, 21].

\section{Conclusions:}

The corrosion rate of carbon steel in aerated $0.1 \mathrm{~N}$ hydrochloric acid increases considerably with increasing Re by increased eddy transport from the bulk of the solution to metal surface. Increasing temperature leads to increase the corrosion rate by decreasing the activation energy for hydrogen reduction reaction and increasing oxygen diffusivity. The addition of organic compounds inhibitors, thiourea, ethylenediamine, diethanolamine and formaldehyde leading to inhibit the corrosion with different efficiencies depending on temperature, Re, and inhibitor concentration. The highest inhibition efficiency is obtained by using thiourea in stationary and flow conditions. Ethelynediamine and diethanolamine show good inhibition efficiency at stationary conditions but its efficiency decreases considerably with increasing Re. Formaldehyde gives reasonable inhibition efficiency in stationary conditions when used in high concentration (2000 ppm) but it gives poor inhibition efficiency under flow conditions. Generally the inhibition efficiency for all inhibitors used, increases with increasing inhibitor concentration. The thiourea 
inhibition efficiency decreases with increasing solution temperature due to the desorption of the adsorbed inhibitor film from the surface.

\section{Nomenclature:}

$\begin{array}{ll}\text { Re } & \text { Reynolds number } \\ \mathrm{d} & \text { pipe diameter (specimen), } \mathrm{m} \\ \mathrm{T} & \text { temperature, }{ }^{\circ} \mathrm{C} \\ \rho & \text { solution density, } \mathrm{kg} / \mathrm{m}^{3} \\ \mu & \text { solution viscosity, } \mathrm{kg} / \mathrm{m} . \mathrm{s} \\ \mathrm{u} & \text { agitation velocity, } \mathrm{m} / \mathrm{s} \\ \mathrm{N} & \text { rotational velocity, revolution/s }\end{array}$




\section{References:}

1. S. S. Mahmoud, "Hydrochloric Acid Corrosion Inhibition of Zn-Al$\mathrm{Cu} \quad$ Alloy by Methyl-Substituted Piperidines", Portugaliae Electrochimica Acta, vol. 26, (2008), pp. 245-256.

2. L. Xianghong, S. Deng, G. Muc, H. Fu, F.Yang” Inhibition effect of nonionic surfactant on the corrosion of cold rolled steel in hydrochloric acid, Corrosion Science 50, (2008),420-430

3. A. O. James, N. C. Oforka, and O. k. Abiola, "Inhibition of Acid Corrosion of Mild Steel by Pyridoxal and Pyridoxol Hydrochlorides", Int. J. Electrochem. Sci., (2007), pp. 278-284.

4. J. Bergman, "Corrosion Inhibitors", the Macmillan Company, New York (1963).

5. G. Butler, H. C. K. Ison, "Corrosion and its Prevention in water Leonard", Hill-London, (1966).

6. L. Xianghong, S. Deng., H. Fu , G. Muc," Synergistic inhibition effect of rare earth cerium(IV) ion and anionic surfactant on the corrosion of cold rolled steel in H2SO4 solution"; Corrosion Science xxx (2008a) $\mathrm{XxX}-\mathrm{XXX}$

7. F. A. Chapion, Corrosion Testing Procedure, 2nd Edition. Chapman and Hall, London, 1964.

8. R.V. Skold, and T. E. Larson, "Measurement of the Instantaneous Corrosion Rate By Means of Polarization Data" Corrosion-NACE, Vol. 13, (1957), pp. 69.

9. M. G Fontana and N. D. Greene, "Corrosion Engineering", London, Third Edition (1987).

10. S. Elbeik, A. C. C. Tseung and A. L. Mackay, "Formation of Calcareous Deposits during the Corrosion of Steel in Sea-water", Corrosion Science", Vol. 26, (1986), pp. 669. 
11. B. K. Mahato, C. Y. Cha, and W. Shemlit, (1980) "Unsteady State Mass Transfer Coefficients Controlling Steel Pipe Corrosion under Isothermal Flow Conditions, Corros. Sci., 20, 421-441.

12. N. Nesic, B.F.M. Pots, J. Postlethwaite, and N. Trevenot, 1995, "WHY DOES GLYCOL INHIBIT CO2 CORROSION", J. Corrosion Science and Eng., Ph. D. Study, Vol.1, Paper 3.

13. L. L Shreir, "Corrosion Handbook", $2^{\text {nd }}$ Edition, Part 1, NewnessButter., London, 1994.

14. Q. J. M. Slaiman and B. O. Hasan, 2005 "Experimental Determination of Corrosion Rate under Turbulent Flow Conditions in Presence of Heat Flux", $5^{\text {th }}$ Chem. Eng. Conference, Amman, Jordan.

15. R. W. Revie and Uhlig. H. H.,. R, Corrosion and Corrosion Control: An Introduction to Corrosion Science and Engineering, $4^{\text {th }}$, Canada, 2008.

16. R. S. Brodkey and H. C. Hershey, Transport Phenomena, $2^{\text {nd }}$ Printing, Mc Graw Hill, New York, 1998.

17. B.K. Mahato, F.R. Stewrd, and L. W. Shimlit, "Steel Pipe Corrosion under Flow Condition- Mass Transfer Correlations with Temperature Effects", Corrs. Sci. J., 8, (1968), pp. 737-749.

18. S. D. Henry and W. M. Scott, "Corrosion in the Petrochemical Industry”, ASM International, First Edition USA,(1999).

19. I. L. Rosenfeld, “Corrosion Inhibitors”, New York, NY: McGraw-Hill, Inc., 1981, pp.371.

20. W. J. Lorenz and F. Mansfeld, "Corrosion Inhibition", R. H. Hausler.ed., NACE, Texas (1988), pp. 7-13.

21. O. O Xometl, N.V. Likhanovab, M.A. Dom'nnguez-Aguilarb, E. Arcec, H. Dorantesc, P. rellanes-Lozadaa," Synthesis and corrosion inhibition of amino acids alkylamides for mild steel in acidic environment" Materials Chemistry and Physics 110 (2008) 344-351. 
22. M. N. Desai, M. B. Desai,, C. B. Shah and S. M. Desai,, Schiff bases as Corrosion Inhibitors for Mild Steel in Hydrochloric Acid Solutions, Corrosion Science, Vol. 26, No. 10, 1986, pp. 827-837.

23. Y. J. Yee, "Green Inhibitors for Corrosion Control", M. Sc. Thesis, University of Manchester Institute of Science and Technology, 2004, pp. 23.

24. A.Y. Musa, A. H. kadhum, M. S. Takriff, A. R. Daud and S. K. Kamarudin, "Evaluation of Ethylenediaminetetra-Acetic Acid DiSodium Salt as Corrosion Inhibitor for Mild Steel in 1m Hydrochloric Acid”, Australian Journal of Basic and Applied Sciences , (2008), pp. 956-960.

25. S. D. Shetty, P. Shetty and H. V. S. Nayak, "The Inhibition Action of $N$-furfuryl- $N$ '-phenyl Thiourea on the Corrosion of Mild Steel in Acid Media", J. Serb. Chem. Soc 71, (2006) pp. 1073-1082.

26. C. B. Shen, S. G. Wang, H. Y. Yang, K. Long and F. H. Wang, "Corrosion and Corrosion Inhibition by Thiourea of Bulk Nanocrystallized Industrial Pure Iron in Dilute $\mathrm{HCl}$ Solution", Corrosion Science 48, (2006) pp. 1655-1665.

27. Q. J. M. Slaiman, B. O. Hasan and H. A. Mahmood, "Corrosion Inhibition of Carbon Steel Under Two-Phase Flow (Water-Petroleum) Simulated by Turbulently Agitated System'. Cand. J. Chem. Eng., Vol. 86, April, 2008. 